\title{
Long-term health-related quality-of-life and symptom response profiles with arformoterol in COPD: results from a 52-week trial
}

This article was published in the following Dove Press journal: International Journal of COPD

\author{
James F Donohue' \\ Vamsi K Bollu² \\ Donald E Stull ${ }^{3}$ \\ Lauren M Nelson ${ }^{4}$ \\ Valerie SL Williams ${ }^{4}$ \\ Michael D Stensland ${ }^{5}$ \\ Nicola A Hanania ${ }^{6}$ \\ 'Department of Pulmonary Diseases \\ and Critical Care Medicine, The \\ University of North Carolina \\ at Chapel Hill, Chapel Hill, NC, \\ ${ }^{2}$ Worldwide Health Economics and \\ Outcomes Research, Bristol-Myers \\ Squibb, Princeton, NJ, ${ }^{3}$ Data Analytics \\ and Design Strategy, ${ }^{4}$ Psychometrics, \\ RTI Health Solutions, Research \\ Triangle Park, NC, ${ }^{5}$ Agile Outcomes \\ Research, Inc., Rochester, MN, \\ ${ }^{6}$ Section of Pulmonary and Critical \\ Care Medicine, Baylor College of \\ Medicine, Houston, TX, USA
}

Background: Symptom severity is the largest factor in determining subjective health in COPD. Symptoms (eg, chronic cough, dyspnea) are associated with decreased health-related quality of life (HRQoL). We evaluated the impact of arformoterol on HRQoL in COPD patients, measured by St George's Respiratory Questionnaire (SGRQ). Post hoc growth mixture model (GMM) analysis examined symptom response profiles.

Methods: We examined data from a randomized, double-blind, parallel-group, 12-month safety trial of twice-daily nebulized arformoterol $15 \mu \mathrm{g}(\mathrm{n}=420)$ versus placebo $(\mathrm{n}=421)$. COPD severity was assessed by Global Initiative for Chronic Obstructive Lung Disease (GOLD) status. GMM analysis identified previously unknown patient subgroups and examined the heterogeneity in response to SGRQ Symptoms scores.

Results: SGRQ Total score improved by 4.24 points with arformoterol and 2.02 points with placebo $(P=0.006)$. Significantly greater improvements occurred for arformoterol versus placebo in SGRQ Symptoms (6.34 vs 4.25, $P=0.031$ ) and Impacts (3.91 vs $0.97, P=0.001$ ) scores, but not in Activity score (3.57 vs 1.75, $P=0.057$ ). GMM identified responders and nonresponders based on the SGRQ Symptoms score. End-of-study mean difference in SGRQ Symptoms scores between these latent classes was 20.7 points $(P<0.001$; 95\% confidence interval: 17.6-23.9). Compared with nonresponders, responders were more likely current smokers $(55.52 \%$ vs $44.02 \%, P=0.0021$ ) and had more severe COPD (forced expiratory volume in 1 second $\left[\mathrm{FEV}_{1}\right]$ : 1.16 vs $1.23 \mathrm{~L}, P=0.0419$ ), more exacerbations ( 0.96 vs $0.69, P=0.0018$ ), and worse mean SGRQ Total (59.81 vs 40.57, $P<0.0001$ ), Clinical COPD Questionnaire (3.29 vs 2.05, $P<0.0001$ ), and Modified Medical Research Council Dyspnea Scale (3.13 vs 2.75, $P<0.0001$ ) scores. Arformoterol-receiving responders exhibited significantly greater improvements in $\operatorname{FEV}_{1}(0.09$ vs $0.008, P=0.03)$ and fewer hospitalizations $(0.13$ vs $0.24, P=0.02)$ than those receiving placebo.

Conclusion: In this study, arformoterol treatment significantly improved HRQoL reflected by SGRQ. For the analysis performed on these data, arformoterol may be particularly effective in improving lung function and reducing hospitalizations among patients who are unable to quit smoking or present with more severe symptoms.

Keywords: St George's Respiratory Questionnaire, growth mixture model, HRQoL, longacting beta agonist

Correspondence: James F Donohue Department of Pulmonary Diseases and Critical Care Medicine, The University of North Carolina at Chapel Hill, CB 7020, 130 Mason Farm Road, Chapel Hill, NC 27599, USA

Tel + I 9199662531

Email jdonohue@med.unc.edu

\section{Introduction}

COPD and other chronic lower respiratory diseases are now the third leading cause of death in the US with 14.8 million people diagnosed with COPD and 12 million estimated to be living with COPD who remain undiagnosed. ${ }^{1,2}$ The economic burden 
of COPD is significant, with projected direct and indirect costs of up to $\$ 49.9$ billion annually in the US; ${ }^{2,3}$ indirect costs account for $\$ 20.5$ billion of this Total, which include additional burden on patients and employers due to lost productivity and on individuals as a result of absenteeism, Activity limitation, and disability. ${ }^{4,5}$

Measures of airflow obstruction (eg, forced expiratory volume in 1 second $\left[\mathrm{FEV}_{1}\right]$ ) have traditionally been used to assess the severity of COPD. Assessing lung function remains important in the diagnosis and design of a treatment plan; however, a more thorough evaluation of the disease including other aspects of impairment and patient-related outcomes may be worthwhile for achieving optimal treatment. ${ }^{6}$ Exacerbations, a worsening of symptoms that often requires hospitalization, are associated with lung function decline and premature mortality. ${ }^{7}$ Additionally, symptoms such as chronic cough and dyspnea are associated with a decline in health-related quality of life (HRQoL) in patients with COPD, contributing to the overall impairment caused by the disease. ${ }^{8,9}$ Dyspnea may also lead patients to reduce activities of daily living, which is a stronger predictor of 3-year survival than even $\mathrm{FEV}_{1}$ and contributes to the impact on overall HRQoL. ${ }^{10}$ Additionally, because of the progressive nature of COPD, the severity of symptoms, which include dyspnea, cough, and sputum production, increases over the course of the disease. ${ }^{11}$ Severity of symptoms is known to be the largest factor in determining subjective health, outweighing demographics, physiological variables such as lung function, and physical function such as exercise capacity. ${ }^{12}$ Thus, successful management of COPD-related symptoms is a vital component of treatment goals. ${ }^{13}$

Inhaled long-acting beta agonists (LABAs) or antimuscarinic agents are commonly prescribed when short-acting agents alone are no longer sufficient to manage the symptoms of COPD. ${ }^{11}$ Arformoterol tartrate is a nebulized LABA that has been approved for maintenance treatment of COPD and has previously been shown to be both safe and efficacious (15 $\mu \mathrm{g}$ twice daily [bid]) for improvement of lung function in a 12-month, double-blind, randomized, placebo-controlled study. ${ }^{14}$ Additionally, in a 12-week, randomized, doubleblind, placebo- and active-controlled trial, arformoterol was shown to improve health status in patients with COPD as measured by the St George's Respiratory Questionnaire (SGRQ). ${ }^{15}$ These findings suggest that use of arformoterol can contribute to the improvement of not only lung function but also clinical symptoms and health status in patients with COPD. Thus, assessing impact of treatment on health status provides useful information regarding disease severity and response to treatment. Further steps remain necessary to better understand the diversity in patient response among those treated for COPD.

Given the heterogeneous nature of COPD, ${ }^{16-18}$ methodologies that may offer the ability for a more detailed characterization of COPD and subgroups that exhibit different response patterns to treatment and consequently differential improvements in health status would be valuable. ${ }^{18}$ Growth mixture models (GMMs) have been used to investigate heterogeneity in treatment response across several diseases. ${ }^{19-22}$ This method analyzes the variability in the response profiles (eg, health status scores) over the treatment period and detects previously unidentified subgroups (or latent classes) of patients. Identifying differential responders could potentially help to better discern effects of treatment. ${ }^{19}$ GMMs have been previously used in COPD clinical trials to identify subgroups of responders and nonresponders based on SGRQ Symptoms scores. ${ }^{22}$

The main objective of this analysis was to compare HRQoL using the SGRQ in patients with moderate-to-severe COPD who were treated with arformoterol or placebo. An additional objective was to identify unknown patient subgroups (latent classes) using the GMM methods. The authors hypothesized that patients would show greater improvement in SGRQ scores with arformoterol treatment compared with placebo and that the GMM analysis would reveal responders and nonresponders with distinct characteristics. Data for these analyses were derived from a Phase III study of efficacy and safety in which patients treated with arformoterol demonstrated a $40 \%$ lower risk of respiratory death or COPD exacerbation-related hospitalization compared with placebo. ${ }^{14}$ The results also indicated that airway function and dyspnea were significantly improved in patients treated with arformoterol versus those treated with placebo and that arformoterol was well tolerated.

\section{Methods}

\section{Study design}

This study consisted of two parts. The first part was an analysis evaluating improvements in HRQoL as measured by change in SGRQ scores from baseline in the aforementioned Phase III trial. The second part was a post hoc analysis using GMM applied to the SGRQ symptom response profiles.

Data for these analyses were derived from a Phase III, multicenter, randomized, double-blind, placebo-controlled, parallelgroup, 12-month outpatient safety trial (NCT00909779). The study evaluated time to COPD-related respiratory death or hospitalization for COPD exacerbation as the 
primary end point. ${ }^{14}$ Briefly, primary inclusion criteria included $\mathrm{FEV}_{1} \leq 65 \%$ predicted volume, $\mathrm{FEV}_{1}>0.50 \mathrm{~L}$, $\mathrm{FEV}_{1} /$ forced vital capacity ratio $\leq 70 \%$, age $\geq 40$ years, smoking history $\geq 15$ pack-years, and baseline breathlessness severity grade $\geq 2$ based on the Modified Medical Research Council (MMRC) Dyspnea Scale score. ${ }^{14}$ Patients who were receiving maintenance corticosteroid combination therapy at screening were switched to corticosteroid monotherapy at the same dose as the previous combination therapy. ${ }^{14}$ Patients were randomly assigned to twice-daily nebulized arformoterol $15 \mu \mathrm{g}(\mathrm{n}=420)$ or matched placebo $(\mathrm{n}=421)$. Treatment with other COPD medications was permitted, with the exception of other LABAs. Efficacy assessments in this Phase III trial included spirometry measures and measure of HRQoL using the SGRQ and the Clinical COPD Questionnaire (CCQ). Assessments with the SGRQ were made at randomization and months 3,6, and 12. COPDrelated hospitalizations and exacerbations, defined as an increase in symptoms that necessitates any change in baseline medication other than bronchodilators (eg, anti-inflammatory agents, antibiotics, supplemental oxygen therapy) or causes the patient to require additional medical attention were also recorded over the 12 months of the study. For additional details, please refer to the primary publication of the trial. ${ }^{14}$

\section{Patient-reported health status}

The SGRQ ${ }^{23,24}$ is one of the most widely used patient-reported outcome measures of health status in COPD, designed for use in patients with fixed and reversible airway obstruction to measure impact on overall health, daily life, and perceived well-being. The SGRQ is a validated measure that consists of 50 items that combine to produce a Total score and three domain scores: Symptoms (frequency and severity), Activity (activities that cause or are limited by breathlessness), and Impacts (social functioning and psychological disturbances resulting from airway disease). SGRQ scores range from 0 (no impairment) to 100 (maximum impairment), reflecting health status over the previous 4 weeks. A 4-point change in mean SGRQ Total score is considered to be clinically meaningful.

\section{SGRQ outcomes}

SGRQ outcomes were analyzed using mixed models for repeated measures (MMRMs) that included terms for treatment, baseline smoking status, baseline SGRQ score, baseline SGRQ-by-visit interaction, visit, and treatment-by-visit interaction. The mean change at each visit was based on the least-square means (LSMs) from the MMRMs. The difference in clinically significant change between arformoterol and placebo was assessed using logistic regressions that included terms for treatment, baseline smoking status, and baseline SGRQ Total score. At each visit, logistic regressions were performed using the observed cases. The last available SGRQ measure for each individual was used for the end point comparison. To characterize the relationship between changes in SGRQ and $F E V_{1}$, we examined change from baseline to end point in SGRQ Total score for subgroups defined by percentage change in $\mathrm{FEV}_{1}$. For all analyses, the two-tailed significance level was set to $\alpha=0.05$.

\section{GMM analysis}

A GMM analysis was conducted to examine the heterogeneity in response to SGRQ Symptoms scores across the four assessment points (baseline, 3 months, 6 months, and 12 months) while controlling for key risk factors (age and smoking status) at baseline. SGRQ Symptoms scores were analyzed in the post hoc GMM analysis because symptoms are most proximal to treatment and thus most likely to show a direct relationship with treatment.

Given large variability in SGRQ Symptoms scores, we hypothesized that there may be subgroups with differential response profiles. The GMM analysis was used to determine whether latent classes (previously unknown or unspecified subgroups) exist in the trial data; subgroup membership was not known a priori but was inferred from the differential patterns of change in data. The heterogeneity of the overall data was treated as being made up of several homogeneous subgroups or classes, each of which was meaningfully different from other classes. Therefore, each post hoc-identified subgroup of patients had distinct SGRQ symptom response profiles. In addition, other characteristics of patients belonging to these latent classes were also evaluated. Stull and Houghton ${ }^{19}$ had provided a detailed description of the GMM methodology.

In the present analyses, GMMs examined the heterogeneity within each treatment arm, controlling for age and smoking status, to see if subgroups of differential responders (eg, responders and nonresponders) could be identified. The best model fit was determined by testing different models specified with different numbers of latent classes. Model fit was evaluated using visual examination and empirical indices: Bayesian information criterion (BIC), sample size-adjusted $\mathrm{BIC}$, and accuracy of latent class assignment using posterior probabilities (entropy). Smaller values of BIC and sample size-adjusted BIC indicate a better model performance and are preferred when choosing the number of latent classes. ${ }^{25}$ 
Although there is no conventional level for the threshold value for entropy, values closer to 1 indicate greater accuracy of latent class assignment. In addition, visual inspection of the latent class trajectories provided insight into the homogeneity of the trajectories within each latent class, as well as the differences between the latent classes. Fit statistics, visual inspection, and descriptive statistics for each latent class were used to determine the number of latent classes and whether the identified classes were clinically meaningful.

Patients were assigned to a single latent class based on the final model's posterior probabilities. ${ }^{25}$ Differences between latent class subgroups were explored. Bivariate comparisons between latent classes of responders, using one-way analyses of variance and chi-square tests, compared the following baseline variables: $\mathrm{FEV}_{1}$, number of exacerbations, SGRQ Total score, CCQ score, and MMRC Dyspnea Scale score.

\section{Ethics approval and consent to participate}

The study was conducted in accordance with the Declaration of Helsinki and good clinical practice guidelines. The following central/local institutional review boards (IRBs) approved the protocol: Copernicus Group IRB, Crescent City IRB, National Jewish Health IRB, Cooper Green Mercy Hospital IRB, Human Subject Research for Baylor College of Medicine and Affiliated Hospitals IRB, Western IRB, and Johns Hopkins IRB. Written informed consent was obtained from all patients.

\section{Results}

As previously reported in the original publication, ${ }^{14}$ there were no significant differences in baseline characteristics between the patients randomized to placebo or arformoterol.

Briefly, patients were in their early 60s and predominantly White. A large majority reported smoking for over 30 years, and approximately half of the patients reported being current smokers. The mean SGRQ (SD) Symptoms score at baseline was 65.8 (18.2) for the arformoterol group and 67.0 (17.6) for the placebo group. The number of patients who completed the 3-, 6-, and 12-month visits was 335 (79.8\%), 304 (72.4\%), and $255(60.7 \%)$ and 295 (70.1\%), 253 $(60.1 \%)$, and $211(50.1 \%)$ for the arformoterol and placebo groups, respectively. ${ }^{14}$

\section{SGRQ outcomes}

Results of the MMRMs showed that the SGRQ Total score at end point improved by 4.24 points from baseline for the arformoterol-treated patients and 2.02 points for the placebo-treated patients (LSM difference vs placebo: -2.22
[95\% confidence interval $\{\mathrm{CI}\}:-3.78$ to -0.66$], P=0.006$; Figure 1A). Similarly, on the SGRQ domains, significantly larger improvements were observed for the arformoterolversus placebo-treated patients in the Symptoms score $(6.34$ vs 4.25 points; LSM difference vs placebo: -2.09 [95\% CI: -3.99 to -0.19 ], $P=0.031$ ) and Impacts score (3.91 vs 0.97 points; LSM difference vs placebo: -2.94 [95\% CI: -4.70 to -1.17 ], $P=0.001)$, but the Activity score differences did not reach statistical significance (3.57 vs 1.75 points; LSM difference vs placebo: -1.822 [95\% CI: -3.70 to -0.06 ], $P=0.057$; Figure 1B-D, respectively). At the end of the study, $42.7 \%$ of the arformoterol-treated patients and $37.3 \%$ of the placebo-treated patients achieved the criteria for minimal clinically important improvement $(P>0.05)$.

The relationship between SGRQ Total score improvement and percentage change in $\mathrm{FEV}_{1}$ is displayed in Figure 2. Although SGRQ Total score improved the most for patients with greatest percentage increases in $\mathrm{FEV}_{1}$, the numerically greater improvement in SGRQ for arformoterol-treated patients was observed across nearly all levels of FEV

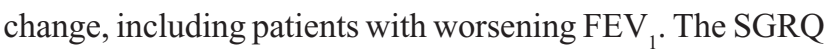
Total score appears to be capturing an aspect of treatment response that supplements the information obtained by measuring change in $\mathrm{FEV}_{1}$.

\section{Exploratory GMMs}

The post hoc GMM analysis identified two latent classes of differential responders among the arformoterol- and placebotreated patients based on the SGRQ Symptoms scores. According to the measures of fit (BIC, adjusted BIC, and entropy indices), a two-class solution provided a better fit to the data than a three-class solution (BIC: 20959.8 vs 20972.8, sample size-adjusted BIC: 20880.4 vs 20871.2, entropy: 0.80 vs 0.76 ). Thus, there were two latent subgroups in each study arm that showed differential SGRQ Symptoms scores at baseline and different trajectories of change. The two latent classes of differential responders identified by GMM will be referred to as responders and nonresponders (Figure 3).

In Figure 3, the two responder groups (one each for arformoterol and placebo) were significantly different from their nonresponder counterparts at baseline (arformoterol: responder SGRQ Symptoms score $=75.3$, nonresponder SGRQ Symptoms score $=45.9, P<0.001$; placebo: responder SGRQ Symptoms score $=75.5$, nonresponder SGRQ Symptoms score $=46.1, P<0.001$ ) and at 12 months (arformoterol: responder SGRQ Symptoms score $=65.0$, nonresponder SGRQ Symptoms score $=48.3, P<0.001$; placebo: responder SGRQ Symptoms score $=68.3$, nonresponder SGRQ Symptoms score $=42.3, P<0.001)$. Moreover, when we compared 

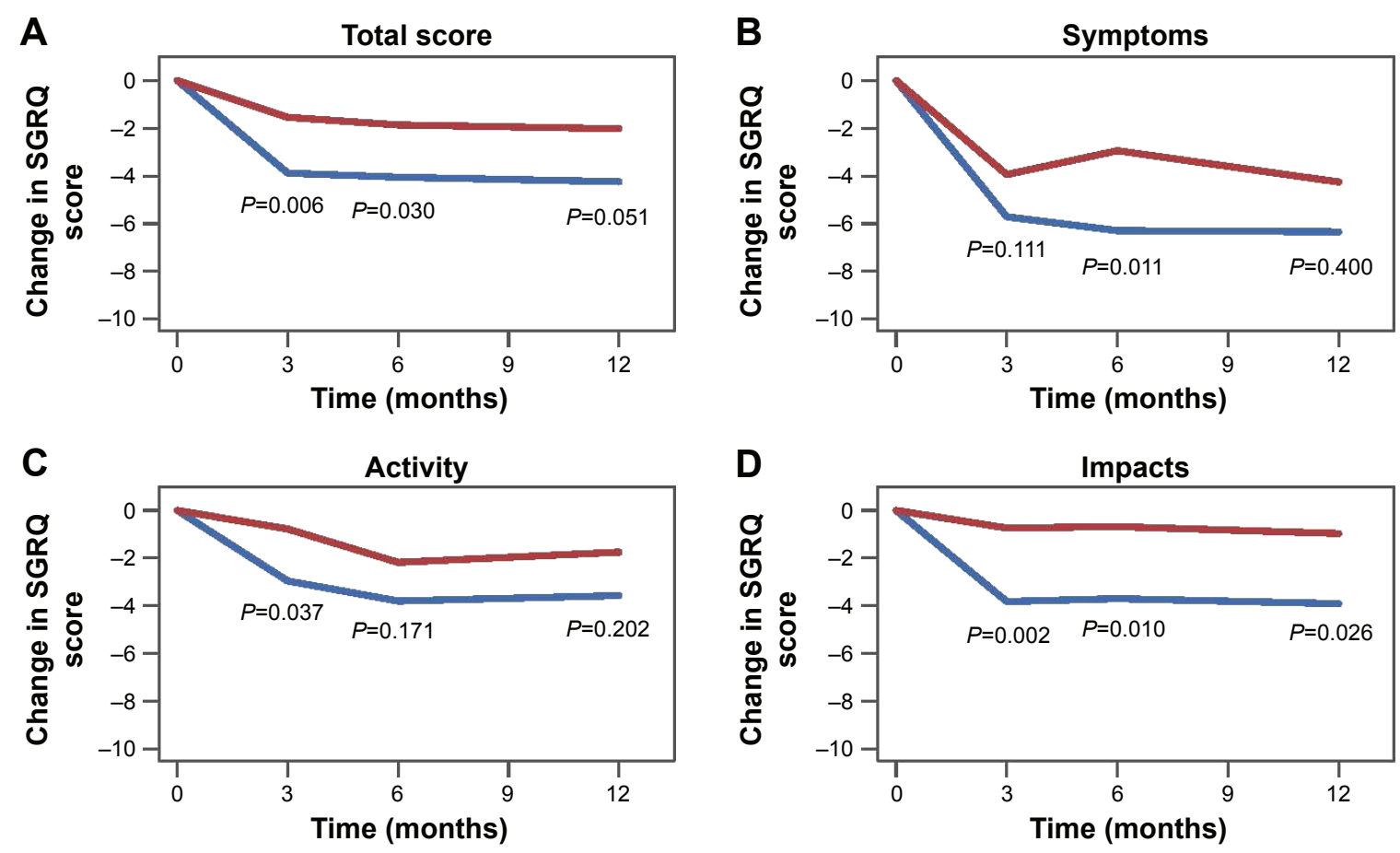

\begin{abstract}
- Placebo - Arformoterol
Figure I Change in SGRQ scores.

Notes: On this patient-completed measure of health status in COPD, the SGRQ Total score (A) showed overall LS mean improvement of 4.24 points for the arformoteroltreated patients and 2.02 points for the placebo-treated patients $(P=0.006)$. Significantly larger improvements were also observed for the arformoterol- versus placebotreated patients on the SGRQ Symptoms score (6.33 vs 4.25 points, $P=0.03$ I; B) and SGRQ Impacts score ( 3.91 vs 0.97 points, $P=0.00$ I; C) but not on the Activity score (3.57 vs 1.75 points, $P=0.057$; D). $P$ values in the figure panels represent comparisons for the 3-, 6-, and 9-month visits. LS mean changes from baseline are also shown for 3 and 6 months.

Abbreviations: LS, least squares; SGRQ, St George's Respiratory Questionnaire.
\end{abstract}

the two responder classes of arformoterol and placebo with the corresponding nonresponder classes, there was a significant difference in the SGRQ Symptoms score change over 12 months between these two responder classes (responder
SGRQ Symptoms score change $=-8.8$, nonresponder SGRQ Symptoms score change $=-1.6, P<0.001)$.

A review of the baseline characteristics revealed multiple significant differences between the latent classes of responders

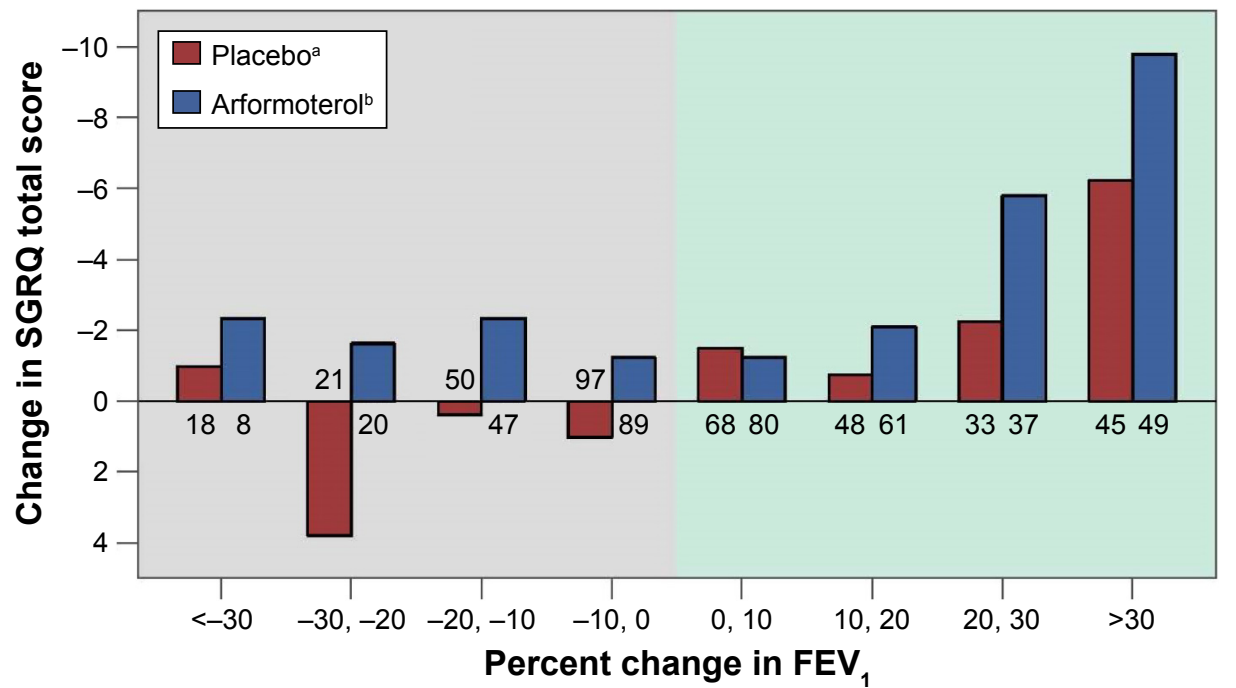

Figure 2 SGRQ Total score change by percentage change in $\mathrm{FEV}_{1}$.

Notes: The relationship between SGRQ Total score improvement and percentage change in FEV, demonstrates that while the SGRQ Total score improved the most for patients with greatest percentage increases in $\mathrm{FEV}_{1}$, the numerically greater improvement in SGRQ for arformoterol-treated patients was observed across all but one level of $\mathrm{FEV}$, change. The number at the base of each bar represents the $\mathrm{n}$ for that group. aPlacebo: $r=-0.17(P=0.00 \mathrm{I}) .{ }^{\mathrm{b}} \mathrm{Arformoterol}$ : $r=-0.12(P=0.018)$.

Abbreviations: $\mathrm{FEV}_{1}$, forced expiratory volume in I second; SGRQ, St George's Respiratory Questionnaire. 


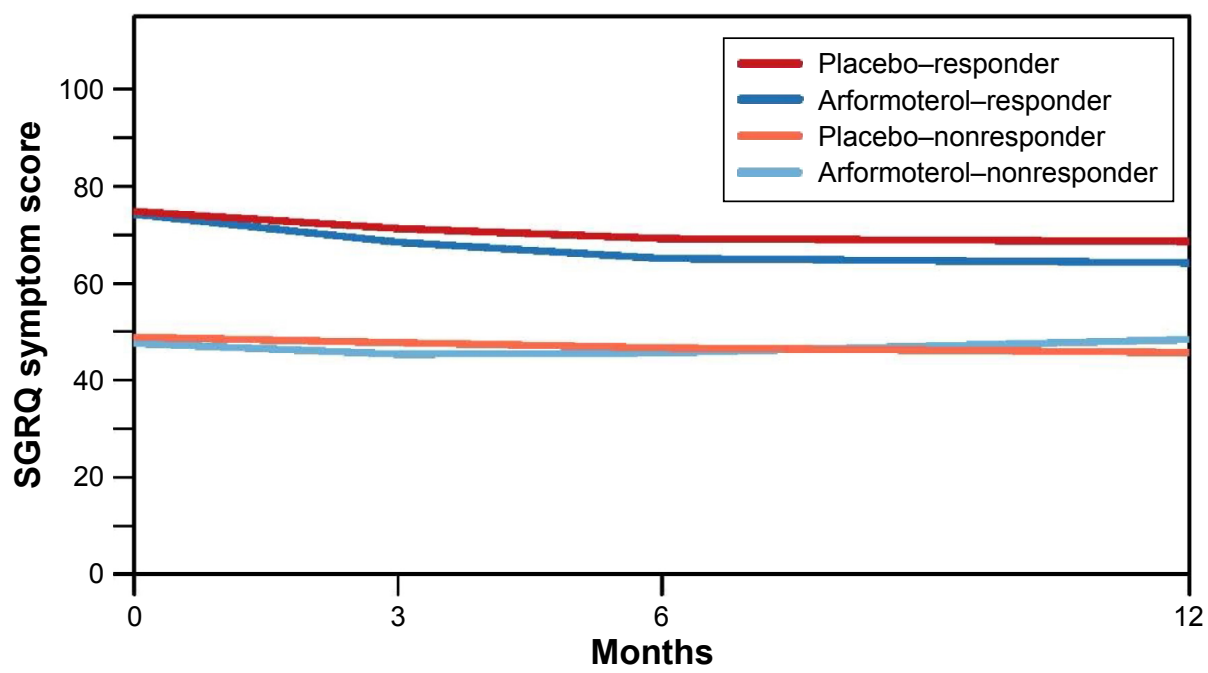

Figure 3 Growth curves of SGRQ Symptoms scores for the two-class solution.

Notes: The two latent classes of differential responders identified by GMM were labeled as responders and nonresponders. SGRQ Symptoms scores were plotted over time for the arformoterol group responders and nonresponders as well as for the placebo group responders and nonresponders.

Abbreviations: GMM, growth mixture model; SGRQ, St George's Respiratory Questionnaire.

and nonresponders (Table 1). Responders exhibited a greater number of symptoms and greater severity of COPD at baseline as measured by $\mathrm{FEV}_{1}(1.16$ vs $1.23 \mathrm{~L}, P=0.0419)$, number of exacerbations ( 0.96 vs $0.69, P=0.0018)$, mean SGRQ Total score (59.81 vs 40.57, $P<0.0001$ ), CCQ score

Table I Descriptive statistics for baseline characteristics by SGRQ symptoms latent class responder status

\begin{tabular}{|c|c|c|c|}
\hline Characteristic & $\begin{array}{l}\text { Responder } \\
\text { latent class } \\
\left(n^{a}=563-571\right)\end{array}$ & $\begin{array}{l}\text { Nonresponder } \\
\text { latent class } \\
\left(\mathrm{n}^{\mathrm{a}}=247-259\right)\end{array}$ & $P$-value \\
\hline $\mathrm{FEV}_{1}$, mean $(\mathrm{SD})$ & $1.16(0.49)$ & $1.23(0.47)$ & 0.0419 \\
\hline Exacerbations, mean (SD) & $0.96(1.29)$ & $0.69(1.09)$ & 0.0018 \\
\hline \multicolumn{4}{|l|}{ SGRQ, mean (SD) } \\
\hline Total & $59.81(14.30)$ & 40.57 (I2.99) & $<0.000$ I \\
\hline Symptoms & $75.43(11.86)$ & 45.97 (II.19) & $<0.000$ I \\
\hline Impacts & $46.13(18.35)$ & $27.43(15.21)$ & $<0.000$ I \\
\hline Activity & $74.54(16.23)$ & $59.56(18.60)$ & $<0.0001$ \\
\hline CCQ, mean (SD) & $3.29(1.09)$ & $2.05(0.93)$ & $<0.000$ I \\
\hline $\begin{array}{l}\text { MMRC Dyspnea Scale } \\
\text { score, mean (SD) }\end{array}$ & $3.13(0.68)$ & $2.75(0.63)$ & $<0.000$ I \\
\hline Age (years), mean (SD) & $63.02(9.4)$ & $65.09(9.4)$ & 0.0033 \\
\hline Current smoker, n (\%) & $317(55.52)$ & I I 4 (44.02) & 0.0021 \\
\hline \multicolumn{4}{|l|}{ GOLD status, n (\%) } \\
\hline B & $450(79.0)$ & $223(86.4)$ & 0.0106 \\
\hline $\mathrm{D}$ & $120(2 \mid .0)$ & $35(13.6)$ & \\
\hline $\begin{array}{l}\text { Arformoterol treatment } \\
(15 \mu \mathrm{g}), \mathrm{n}(\%)\end{array}$ & $280(49.0)$ & $137(52.9)$ & \\
\hline Placebo, n (\%) & $291(51.0)$ & $122(47.1)$ & \\
\hline
\end{tabular}

Notes: Patients had to have MMRC Dyspnea Scale score $\geq 2$ to participate in the study. Latent classes are based on GMM analysis of the SGRQ Symptoms scores. aSample sizes vary across characteristics due to missing data.

Abbreviations: CCQ, Clinical COPD Questionnaire; $\mathrm{FEV}_{1}$, forced expiratory volume (L) in I second; GMM, growth mixture model; GOLD, Global Initiative for Chronic Obstructive Lung Disease; MMRC, Modified Medical Research Council; SGRQ, St George's Respiratory Questionnaire.
(3.29 vs $2.05, P<0.0001)$, and MMRC Dyspnea Scale score (3.13 vs $2.75, P<0.0001)$. Responders were also more likely to be current smokers ( $55.5 \%$ vs $44.02 \%, P=0.0021)$ and fall under Global Initiative for Chronic Obstructive Lung Disease (GOLD) status D (21.0\% vs $13.6 \%)$.

Latent class responders treated with arformoterol were compared with latent class responders treated with placebo on patient outcome measures (Figure 4). The arformoterol and placebo responders demonstrated comparable improvements in symptoms $(-10.3$ vs $-7.2, P>0.05)$ and a similar mean number of exacerbations ( 0.55 vs $0.69, P>0.05$; Figure 4). However, the arformoterol-treated responders exhibited significantly greater improvements in $\mathrm{FEV}_{1}(0.09$ vs $0.008 \mathrm{~L}, P=0.03$ ) and significantly fewer hospitalizations ( 0.13 vs $0.24, P=0.02$; Figure 4 ).

\section{Discussion}

In this analysis of patient-reported outcomes from a large safety study, COPD patients treated with arformoterol reported significant improvement in HRQoL as measured by the SGRQ Total score as well as the Symptoms and Impacts domain scores. In addition, while not significantly different between groups, a higher proportion of patients in the arformoterol group than in the placebo group met the criterion for the minimal clinically important difference of $4 \%$ ( $\geq-4$ units) on these scores.

The HRQoL improvements reported here are consistent with a previous study of COPD patients treated with arformoterol. ${ }^{15}$ Although the previous trial was of shorter duration (12 weeks), Baumgartner et al reported mean SGRQ Total 


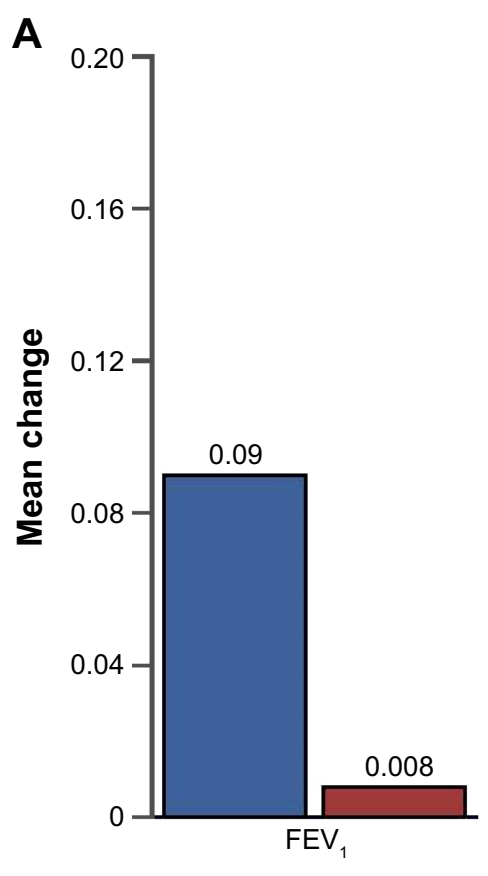

B

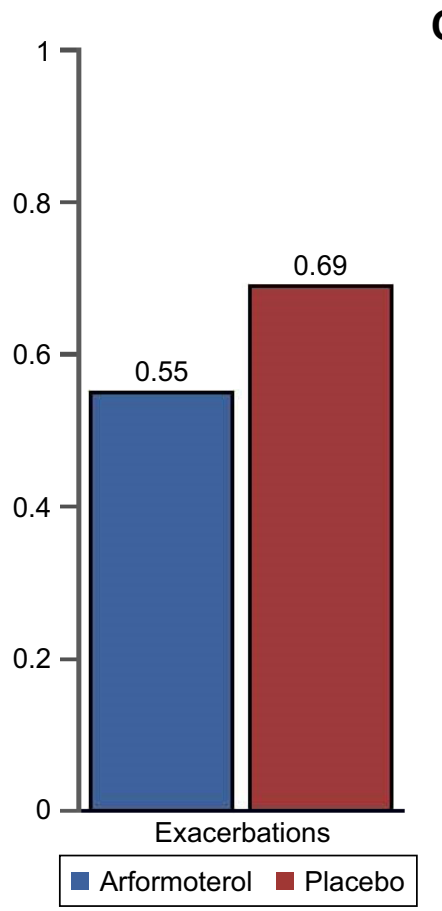

C

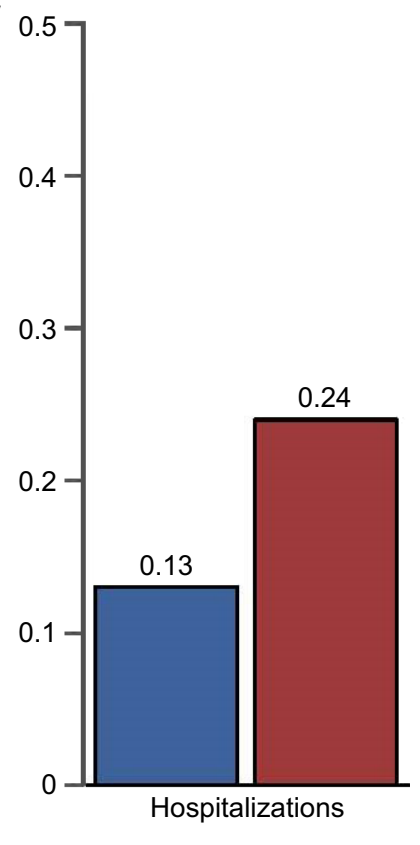

Figure 4 Change in mean FEV, exacerbations, and hospitalizations for latent class responders treated with arformoterol versus latent class responders treated with placebo. Notes: (A) The arformoterol-treated responders exhibited significantly greater improvements in $\mathrm{FEV}_{1}(0.09$ vs $0.008, P=0.03)$. (B) The arformoterol and placebo responders demonstrated a similar mean number of exacerbations $(0.55 \mathrm{vs} 0.69, P>0.05)$. (C) The arformoterol-treated responders had significantly fewer hospitalizations $(0.13$ vs 0.24 , $P=0.02$ ).

Abbreviation: $\mathrm{FEV}_{1}$, forced expiratory volume in I second.

score changes from baseline to week 6 of -2.6 and -3.6 for patients treated with arformoterol 15 and $25 \mu \mathrm{g}$ twice daily, respectively, and -1.2 in the placebo group. ${ }^{15}$ In both arformoterol groups, the greatest improvements were observed in the Symptoms domain of the SGRQ. The current study found a similar pattern of results. The greatest improvement was in the Symptoms domain, with a mean change from baseline of -6.33 in the arformoterol group and -4.25 in the placebo group at trial end.

At the end of the present study, $42.7 \%$ of patients treated with arformoterol achieved at least a 4-point improvement in SGRQ Total score (minimal clinically important difference) versus $37.3 \%$ of patients treated with placebo. The improvement in SGRQ Total score at 12 months ( -2.2 vs placebo) is consistent with the mean improvement in SGRQ Total score ( -2.3 vs placebo) reported in a review of 26 randomized controlled trials that compared LABAs with placebo in the treatment of COPD. ${ }^{26}$ The trials from this review had a large range for observation periods; reports were as early as 3 months to as long as 3 years. However, the majority of the results described were after 6 months.

Our analysis also showed greater improvements on the Impacts domain of the SGRQ in patients treated with arformoterol compared with patients treated with placebo.
While improvements were observed in Activity score in the arformoterol group compared with the placebo group, the difference did not reach statistical significance. This could potentially be explained by the generally older population ( $\geq 63$ years old) in this study and the long smoking history of the patients ( $30+$ years in $80 \%$ of patients), with approximately half of patients reported to be current smokers.

The exploratory GMM analyses conducted as part of this post hoc study efficiently identified differential responders on the SGRQ Symptoms domain within all patient responses over time, revealing two distinct and internally homogeneous cohorts. The groups identified in these GMM analyses were labeled as responders and nonresponders due to their different observed patterns of symptom improvement. GMM analyses do not require establishing an a priori threshold for "responder", and they eliminate the need to try different cut-points on outcomes variables to identify differential responders, which results in multiplicity and violates assumptions of independence of tests.

The responders and nonresponders differed on multiple important baseline variables. The responder group could be characterized as experiencing greater initial COPD severity that had a greater impact on HRQoL. In addition, the responder group was represented by a significantly higher percentage of 
current smokers and GOLD status D patients and exhibited significantly higher CCQ and MMRC scores compared with nonresponders.

Among the symptom responders, arformoterol-treated patients had greater improvements in lung function and fewer hospitalizations than placebo-treated patients. Hospitalizations represent a worse clinical outcome for patients and make up the largest portion of the direct treatment costs of COPD. Reducing symptoms and hospital admissions could help improve patients' outcomes and quality of life while reducing the direct and indirect economic burden of COPD. Treating patients who have a baseline profile similar to the responders with arformoterol could help reduce symptoms and reduce hospitalizations, but more research is needed to replicate and extend these findings.

Stull et $\mathrm{al}^{22}$ conducted a GMM analysis across three studies of indacaterol, one 12-month study and two 6-month studies. The 12-month study resulted in three latent class assignments, while the two 6-month studies resulted in two latent class assignments (nonresponder and responder) similar to the present study. While the findings in the present study are generally consistent with those reported by Stull et al, there were some important differences between the studies with regard to baseline SGRQ Symptoms domain scores. In the report by Stull et al, the responder groups in the two 6-month studies were less symptomatic than the nonresponder groups at baseline (SGRQ Symptoms score: 50.5 and 48.3 vs 73.7 and 79.3, respectively, $P<0.001$ for both). In the present study, the inverse was found. In the present study, the responder group was more symptomatic than the nonresponder group at baseline ( 75.4 vs 46.0, respectively). One could speculate that the different pattern of GMM results across the current study and the indacaterol study suggests that arformoterol may be more effective among patients with a more severe baseline profile and indacaterol may be more effective among those with less severe symptoms, but head-to-head studies are needed to draw any meaningful conclusions.

Our study adds to the present knowledge of COPD management, highlighting the importance of assessing health status in addition to lung function to obtain a more accurate evaluation of patient outcome and treatment. In addition, identifying and characterizing differential responders may potentially help to better assess treatment effects.

Our study has several limitations, which include the fact that there were a meaningful number of treatment discontinuations during the 12-month study. In addition, concomitant medication treatments were allowed (consistent with usual clinical care), which could cloud the assessment of treatment effect. Study findings may not be generalizable to a broader population, partly due to exclusion of some patients based on background LABA/inhaled corticosteroid therapy. However, the consistency of the findings with other studies of the effect of LABAs on the SGRQ lends strength to the conclusions.

The post hoc GMM analysis has inherent limitations. Because it was an exploratory analysis of a single trial, there was no way to confirm the presence of the same number and characteristics of latent classes in a second study. Thus, we relied on the fit statistics and visual examination of the latent classes. GMMs become a powerful tool when they can be used in more than one study to explore and confirm the results. A second limitation is that the SGRQ Symptoms domain as a stand-alone subscale is not validated. However, this domain assesses patients' symptom experience and is more likely to demonstrate a direct relationship with treatment. ${ }^{19,22}$ Although not a limitation of the method, a note of caution is in order: use of this methodology requires a robust understanding of latent growth modeling and structural growth modeling to identify nuances of the model design and interpret outputs for possible issues. ${ }^{19}$ The findings reported here may add information to those reported by Stull et $\mathrm{al}^{22}$ and serve as a partial foundation from which confirmatory analyses or clinical trials could be used. ${ }^{19,20,22}$ However, having partially replicated previous findings supports our confidence in these results.

\section{Conclusion}

In these analyses of data from a large placebo-controlled clinical trial in patients with COPD, improvements in arformoterol-treated patients were observed for the SGRQ Total score as well as the Symptoms and Impacts domain scores. Based on the GMM results, we identified two underlying subgroups that determined pattern of symptoms change: responders who at baseline were more impaired in $\mathrm{FEV}_{1}$ (mean: 1.16 vs $1.23 \mathrm{~L}, P=0.042$ ) and demonstrated more limitations based on SGRQ scores (mean: 59.81 vs 40.57, Symptoms score 75.43 vs 45.97 , Impacts score 46.13 vs 27.43 , and Activity score 74.54 vs 59.56 , all $P<0.0001$ ) compared with nonresponders. Treatment with arformoterol appeared to decrease hospitalizations and increase $\mathrm{FEV}_{1}$ for patients with more severe symptoms at baseline who were unable to quit smoking. More research is needed to better understand and optimize treatment for patients with COPD.

\section{Data sharing statement}

The datasets during and/or analyzed during the current study are available from the corresponding author on reasonable request. 


\section{Acknowledgments}

The study was funded by Sunovion Pharmaceuticals Inc. The authors wish to thank Claudette Knight, PharmD, and D. Michele Nikoloff, $\mathrm{PhD}$, of Percolation Communications LLC for providing medical editorial assistance. Development of this manuscript was sponsored by Sunovion Pharmaceuticals Inc.

\section{Author contributions}

All authors have contributed substantially to the design of the study, acquisition, analysis, and interpretation of data and to the drafting of the manuscript or revising it critically and gave final approval of the version to be submitted.

\section{Disclosure}

JFD receives consultancy and advisory fees from Sunovion Pharmaceuticals Inc. MDS is a full-time employee and sole stockholder in Agile Outcomes Research, Inc., a research consulting firm contracted by Sunovion Pharmaceuticals Inc. to assist with this research. DES, LMN, and VSLW are employees of RTI Health Solutions, a research consulting firm contracted by Sunovion Pharmaceuticals Inc. to assist with this research. RTI Health Solutions is a research unit of RTI International, a not-for-profit research institute. At the time of this research, VKB was an employee of Sunovion Pharmaceuticals Inc. NAH has served as a consultant for Sunovion Pharmaceuticals Inc., and his institution has received research grant funding on his behalf. The authors report no other conflicts of interest in this work.

\section{References}

1. Kochanek KD, Murphy SL, Jiaquan X, Arias E. Mortality in the United States, 2013. National Center for Health Statistics (NCHS) Data Brief. No $178 ; 2014$. Available from: http://www.cdc.gov/nchs/data/databriefs/ db178.pdf. Accessed May 9, 2017.

2. National Heart, Lung and Blood Institute. Morbidity and Mortality: 2012 Chart Book on Cardiovascular, Lung, and Blood Diseases. Bethesda, MD: National Institutes of Health; 2012. Available from: https://www. nhlbi.nih.gov/files/docs/research/2012_ChartBook_508.pdf. Accessed May 9, 2017.

3. Foster TS, Miller JD, Marton JP, Caloyeras JP, Russell MW, Menzin J. Assessment of the economic burden of COPD in the U.S.: a review and synthesis of the literature. COPD. 2006;3(4):211-218.

4. American Lung Association. Trends in COPD: Chronic Bronchitis and Emphysema: Morbidity and Mortality. 2013. Available at http://www. lung.org/finding-cures/our-research/trend-reports/copd-trend-report.pdf. Accessed May 9, 2017.

5. Patel JG, Nagar SP, Dalal AA. Indirect costs in chronic obstructive pulmonary disease: a review of the economic burden on employers and individuals in the United States. Int J Chron Obstruct Pulmon Dis. 2014;9:289-300.

6. Jones P, Miravitlles M, van der Molen T, Kulich K. Beyond FEV(1) in COPD: a review of patient-reported outcomes and their measurement Int J Chron Obstruct Pulmon Dis. 2012;7:697-709.
7. Rennard SI, Farmer SG. Exacerbations and progression of disease in asthma and chronic obstructive pulmonary disease. Proc Am Thorac Soc. 2004;1(2):88-92.

8. Miravitlles M, Molina J, Naberan K, et al. Factors determining the quality of life of patients with COPD in primary care. Ther Adv Respir Dis. 2007;1(2):85-92.

9. Shavro SA, Ezhilarasu P, Augustine J, Bechtel JJ, Christopher DJ. Correlation of health-related quality of life with other disease severity indices in Indian chronic obstructive pulmonary disease patients. Int $J$ Chron Obstruct Pulmon Dis. 2012;7:291-296.

10. Reardon JZ, Lareau SC, ZuWallack R. Functional status and quality of life in chronic obstructive pulmonary disease. Am J Med. 2006; 119(10 suppl 1):32-37.

11. Global Initiative for Chronic Obstructive Lung Disease. Global Strategy for the Diagnosis, Management and Prevention of COPD. 2015. Available from: http://goldcopd.org/global-strategy-diagnosis-managementprevention-copd-2016/. Accessed May 9, 2017.

12. Bentsen SB, Henriksen AH, Wentzel-Larsen T, Hanestad BR, Wahl AK. What determines subjective health status in patients with chronic obstructive pulmonary disease: importance of symptoms in subjective health status of COPD patients. Health Qual Life Outcomes. 2008;6:115.

13. van der Molen T, Miravitlles M, Kocks JW. COPD management: role of symptom assessment in routine clinical practice. Int J Chron Obstruct Pulmon Dis. 2013;8:461-471.

14. Donohue JF, Hanania NA, Make B, et al. One-year safety and efficacy study of arformoterol tartrate in patients with moderate to severe COPD. Chest. 2014;146(6):1531-1542.

15. Baumgartner RA, Hanania NA, Calhoun WJ, Sahn SA, Sciarappa K, Hanrahan JP. Nebulized arformoterol in patients with COPD: a 12-week, multicenter, randomized, double-blind, double-dummy, placebo- and active-controlled trial. Clin Ther. 2007;29(2):261-278.

16. Agusti A, Calverley PM, Celli B, et al. Characterisation of COPD heterogeneity in the ECLIPSE cohort. Respir Res. 2010;11:122.

17. Agusti AG. COPD, a multicomponent disease: implications for management. Respir Med. 2005;99(6):670-682.

18. Wedzicha JA. The heterogeneity of chronic obstructive pulmonary disease. Thorax. 2000;55(8):631-632.

19. Stull DE, Houghton K. Identifying differential responders and their characteristics in clinical trials: innovative methods for analyzing longitudinal data. Value Health. 2013;16(1):164-176.

20. Stull DE, Houghton K, Petrillo J. Innovative data analysis for demonstrating product value: analysis of heterogeneity in treatment response in clinical trials. ISPQR Connect. 2013;19:5-8.

21. Willke RJ, Zheng Z, Subedi P, Althin R, Mullins CD. From concepts, theory, and evidence of heterogeneity of treatment effects to methodological approaches: a primer. BMC Med Res Methodol. 2012;12:185.

22. Stull DE, Wiklund I, Gale R, Capkun-Niggli G, Houghton K, Jones P. Application of latent growth and growth mixture modeling to identify and characterize differential responders to treatment for COPD. Contemp Clin Trials. 2011;32:818-828.

23. Jones PW, Quirk FH, Baveystock CM. The St George's Respiratory Questionnaire. Respir Med. 1991;85(suppl B):25-31; discussion 33-37.

24. Jones PW, Quirk FH, Baveystock CM, Littlejohns P. A self-complete measure of health status for chronic airflow limitation. The St. George's Respiratory Questionnaire. Am Rev Respir Dis. 1992;145:1321-1327.

25. Tofighi D, Enders CK. Identifying the correct number of classes in growth mixture models. In: Hancock G, Samuelson K, editors. Advances in Latent Variable Mixture Models. Charlotte, NC: Information Age Publishing; 2008:317-341.

26. Kew KM, Mavergames C, Walters JA. Long-acting beta2-agonists for chronic obstructive pulmonary disease. Cochrane Database Syst Rev. 2013;10:CD010177 


\section{Publish your work in this journal}

The International Journal of COPD is an international, peer-reviewed journal of therapeutics and pharmacology focusing on concise rapid reporting of clinical studies and reviews in COPD. Special focus is given to the pathophysiological processes underlying the disease, intervention programs, patient focused education, and self management protocols.

This journal is indexed on PubMed Central, MedLine and CAS. The manuscript management system is completely online and includes a very quick and fair peer-review system, which is all easy to use. Visit http://www.dovepress.com/testimonials.php to read real quotes from published authors.

Submit your manuscript here: http://www.dovepress.com/international-journal-of-chronic-obstructive-pulmonary-disease-journal 